\title{
GoingAbroad 3D: descrição de um protótipo de jogo educacional digital
}

\section{Going Abroad 3D: a digital serious game prototype description}

\author{
SUSANA CRISTINA DOS REIS \\ Universidade Federal de Santa Maria \\ QUÉLVIN SIQUEIRA GAZEN
}

Universidade Federal de Santa Maria

\begin{abstract}
Resumo. Jogos digitais potencializam a aprendizagem contextualizada e significativa, bem como proporcionam a imersão e a agência do jogador na resolução de desafios propostos durante o ato de jogar. Com base nessas premissas, iniciamos uma pesquisa exploratória selecionando pressupostos teóricos que fundamentam o design do jogo Going Abroad $3 D$ como um estudo de caso. A análise de jogos comerciais imersivos e de pressupostos teóricos nos permitiram identificar elementos essenciais que orientaram a elaboração do projeto desse jogo educacional para uso em aulas de Inglês. Os resultados estão aplicados no design da interface do jogo e na elaboração de sistemas do jogo, o qual conta em seu protótipo, o menu, a cena introdutória e cenários introdutórios do jogo com desafios implementados.
\end{abstract}

Palavras-chave: Going abroad 3D. Protótipo. Desenvolvimento. Jogos Sérios. Inglês.

Abstract. Digital games potentialize a meaningful and contextualized learning process, as well as providing the player with immersion and agency in the resolution of challenges presented during the gameplay. Based on these premises, we began an exploratory research, selecting theoretical assumptions that grounded the game level design of Going Abroad 3D as a case study. The analysis of renowned immersive commercial games, and the theoretical references allowed us to identify essential elements that guided the development of this serious game for use in English classes. The results are applied into the design of the game's interface and in the game' system, and it presents till now in its prototype a menu, a cutscene, the initial scenarios and its challenges implemented.

Keywords: Going Abroad 3D. Prototype. Development. Serious games. English. 


\section{Introdução}

Estudos recentes na área de ensino de línguas mediado por tecnologias digitais mostram que o uso de jogos digitais em sala de aula pode ser uma alternativa para favorecer o contato com diferentes linguagens encontradas nesses artefatos digitais, a interação, bem como a aprendizagem contextualizada e significativa (SYKES; REINHARDT, 2013).

Além desses benefícios, estudos prévios evidenciam que jogos podem potencializar também o trabalho em equipe, a busca pela construção colaborativa do conhecimento, a imersão e a agência do jogador na resolução de problemas propostos durante o ato de jogar (GEE 2005; SYKES; REINHARDT, 2013; GOMES; REIS, 2019; REIS, 2017).

Com base nessas premissas, observamos que jogos não só trazem benefícios, mas também desafios para professores e alunos. Com relação aos professores, o uso desses recursos se torna desafiador quanto a sua inclusão na prática de ensino, pois não há metodologias de ensino que orientam com clareza como ensinar e/ou explorá-los na sala de aula (REIS, 2017; REIS; GOMES, 2019). Já com relação aos alunos, estudos mostram que tanto usar quanto criar jogos, pode ser uma atividade que desperta a motivação, permitir a agência do aluno na resolução dos problemas, como também os tornar ativos e engajados no seu processo de aprendizagem(GOMES, 2017; GOMES; REIS, 2019; LINCK, 2018).

Em vista disso, em estudos anteriores, propostos e publicados por participantes de nosso grupo de pesquisa (REIS, 2017; REIS; GOMES, 2015; LINCK, 2018; LINCK; REIS, 2019), evidenciam a importância de ao utilizar jogos em sala de aula possibilitar a construção conjunta e interdisciplinar de projetos com os alunos, por meio de ações de pesquisa, ensino e de extensão na Universidade. Com a intenção de dar continuidade a essa proposta e, considerando a pouca existência de jogos educacionais gratuitos, que sejam motivantes para integrar em aulas de língua inglesa, entendemos a importância de propor novos jogos que favoreçam a imersão do aluno/jogador em situações comunicativas, promovam a prática da língua-alvo, sem colocar em testagem apenas a compreensão e a tradução de vocabulários, como recorrentemente encontramos em propostas de jogos educacionais para o ensino da língua inglesa.

Por isso, neste artigo partimos do seguinte problema de pesquisa: quais adaptações são necessárias no processo de roteirização/criação da narrativa e do level design em um jogo educacional para que ele se torne engajador e divertido? A partir desse questionamento, buscamos contribuir com as pesquisas na área e apresentamos a versão protótipo do jogo educacional nomeado como Going Abroad 3D (doravante GA 3D), em desenvolvimento junto com alunos por meio de um projeto de pesquisa.

A temática do jogo GA 3D explora o universo acadêmico, mais especificamente, ressalta a importância do aluno em participar de ações de pesquisa e intercâmbio acadêmico, integrando a esse tema elementos de ficção científica, com vista a provocar o engajamento e a inserção do aluno em um ambiente virtual imersivo, por meio de uma história instigante. Para elaborar essa 
narrativa, utilizamos como referência o estudo de Campbell (2004), para fundamentar e planejar as diferentes fases do jogo.

É oportuno salientar que o GA ainda está em desenvolvimento, portanto, neste artigo abordamos as implementações realizadas, até o momento, no Game Design do GA 3D. As quatro seções encontradas aqui buscam discutir os seguintes aspectos: a primeira, apresenta os materiais e métodos utilizados para orientar o desenvolvimento da pesquisa; segunda, traz os pressupostos teóricos que fundamentam o design gráfico e pedagógico do GA; a terceira, relata as implementações feitas no jogo como resultado do estudo; por último, as considerações finais sobre este trabalho e possíveis rumos para a pesquisa e o processo de desenvolvimento.

\section{Materiais e Métodos}

Esta pesquisa está em desenvolvimento pelo GrPesq/CNPq Núcleo de Pesquisa, Ensino e Aprendizagem de Línguas a Distância (NUPEAD), na Universidade Federal de Santa Maria, dentro das ações do projeto de pesquisa Análise e Produção de Aplicativos e Jogos Digitais Educacionais Interdisciplinares para o ensino de línguas na Universidade ${ }^{1}$. Nesse projeto, buscamos tanto analisar jogos digitais para uso em sala de aula, quanto desenvolver jogos e aplicativos para uso na Educação. O projeto supracitado adota os procedimentos metodológicos de uma pesquisa do tipo exploratória e bibliográfica, porque parte da literatura expoente na área para fundamentar a análise e o desenvolvimento de um jogo educacional digital.

Para isso, a primeira etapa da pesquisa, realizada nos anos de 2018-2019, por meio do método de estudo de caso, selecionou jogos digitais em $2 \mathrm{D}^{2}$ e em $3 \mathrm{D}$ disponíveis no mercado para analisá-los com relação a sua narrativa e interface gráfica. Os critérios para escolha dos jogos foram os seguintes: versão/localização do jogo em língua inglesa; gratuidade; ser disponível para diferentes plataformas tais como Windows e Android. Além desses critérios, procuramos identificar jogos que apresentavam gameplay potencialmente engajante, design gráfico atrativo, com alta definição que pudessem nos ajudar a perceber a qualidade e a vontade do jogador de explorá-lo. Para avaliar esses aspectos, consideramos as categorias de análise adaptadas da metodologia MEEGA+ (PETRI; GRESSE VON WANGENHEIM; BORGATTO, 2019), por meio da avaliação feita pelos membros da equipe de pesquisa do Jogo.

Por esta pesquisa tratar-se de um estudo de natureza descritiva e aplicada, partimos de algumas perguntas de pesquisa para orientar a análise dos objetos em estudo, tais como: a) Como o game design e a narrativa em jogos digitais comerciais são propostos?; b) De que maneira os movimentos retóricos encontradas nas estruturas narrativas dos jogos digitais analisados servem como base para o entendimento da criação de roteiros para jogos educacionais?; c) Quais elementos linguísticos (textuais, imagéticos, animações, multimodais)

\footnotetext{
1 Registro GAP CAL/UFSM, sob no 051712.

${ }^{2}$ A análise de Jogos em 2D já foi publicada (GAZEN; REIS; GOMES, 2019), porém resultados com relação aos jogos em 3D ainda são iniciais, em vista disso estes não serão reportados ainda neste estudo.
} 
são utilizados na composição de um jogo digital em 3D? d) Como organizar as tarefas da equipe para que o jogo seja desenvolvido dentro do prazo previsto?

A segunda etapa da pesquisa envolveu o desenvolvimento do protótipo. Neste artigo, reportamos os procedimentos adotados para elaborar o protótipo do jogo GA 3D, para isso primeiramente retomamos os pressupostos teóricos que foram basilares para orientar o design gráfico e os sistemas do jogo. Após, definirmos a narrativa e os desafios do jogo, iniciamos o desenvolvimento, utilizando como software o Unity.

Como ação inicial, os bolsistas e participantes do projeto ${ }^{3}$ foram divididos em equipes, sendo cada grupo responsável por criar partes do jogo. Por exemplo, os programadores mais experientes com a ferramenta Unity envolveram-se na criação dos sistemas do jogo, tais como o de diálogo, inventário, sistema de pontuação e energia. Outro grupo envolveu-se na elaboração dos elementos visuais do jogo, tais como criação de itens coletáveis em 3D, construção do menu, de itens do cenário gráfico do jogo, e produção de animações e avatares.

Na seção de análise e resultados descrevemos o protótipo do jogo GA 3D e apresentamos as adaptações feitas até o presente momento. É importante informar que testagem inicial do protótipo já foi realizada, porém envolveu apenas dois jogadores, sendo um aluno do Ensino Médio e outro universitário, os quais estão na faixa etária de 15 a 21 anos, ambos com perfil de jogadores experientes, tanto com uso de jogos em PC quanto de consoles, representando assim o público alvo do jogo. Devido a isso, neste artigo nos limitaremos a descrição do jogo, sem apresentar ainda dados de avaliação da prototipagem.

\section{Fundamentação teórica para orientar o desenvolvimento do GA 3D}

Para produzirmos o GA 3D recorremos aos diferentes pressupostos teóricos para fundamentar e planejar o desenvolvimento do protótipo. Esses pressupostos selecionados no formato de artigos e livros discutem aspectos essenciais para orientar o processo de desenvolvimento de jogos educacionais (GEE, 2005; CAMPBELL, 2004; FIELD, 2001; SYKES; REINHARDT, 2013).

Um dos estudos basilares do GA 3D é o de Gee (2005) que descreve os aspectos de bons jogos e os auxilia na identificação de diferentes mecânicas e requisitos, os quais podem ser encontrados no gameplay de diferentes jogos. Entre esses requisitos, estão aqueles que enfatizam a necessidade de chamar a atenção, provocar o engajamento e a interação do jogador durante $o$ ato de jogar. Para isso, o estudo supracitado descreve as características necessárias para que jogos tenham uma jogabilidade agradável, bem como apresentem um nível moderado de desafios e recompensas atribuídas aos esforços do jogador durante o jogo.

Para Gee (2005), além desses quesitos, todo o bom jogo precisa prever uma boa ordenação de problemas a serem resolvidos pelo jogador durante o ato de jogar. Esse quesito foi observado também pela análise realizada tanto em jogos 2D quanto em 3D. Com isso, consideramos ser essencial na produção de um jogo educacional planejar e implementar diferentes desafios que

\footnotetext{
${ }^{3}$ Agradecemos a equipe que atua junto ao projeto, especialmente ao Renan Cechin Junior (Bolsista PROBIC/FAPERGS 2020), Bruno Gottlieb, Leonardo Chagas do Nascimento, Elizabeth Nwogo Caroline Uzoegwu e Gláucio Sales (Bolsista PROBIC/FAPERGS 2019).
} 
remetem às diferentes situações comunicativas em que o aluno-jogador poderia vivenciar também no mundo real.

Outro estudo basilar do presente estudo é o de Campbell (2004), que orientou a construção da história implementada no jogo GA 3D. Essa obra nos deu suporte para elaborarmos a descrição dos arquétipos para personagens e definirmos o mapeamento da estrutura narrativa, a partir da conhecida Jornada do Herói, geralmente citada em narrativas fictícias famosas de livros e jogos. No GA 3D recriam-se situações comunicativas possivelmente vivenciáveis em um contexto universitário, tendo como finalidade (re)contextualizar possíveis interações e falas que acontecem no contexto universitário. Além disso, buscamos incluir nessa narrativa alguns elementos da fiç̧ão, que colocam o jogador como um possível herói da estória, buscando aliar à narrativa e o lúdico pela resolução de problemas que o jogador encontrará pela interação com outros avatares no cenário.

Também, durante o processo de (re)escrita da narrativa nos beneficiamos do livro de Field (2001), que explica o passo a passo de um movimento de roteirização. A partir dessa obra, organizamos a edição de documentos que envolvem a produção textual da narrativa, de modo a tornar a sistematização do trabalho em equipe de desenvolvimento mais fluida e direta.

o GA é um jogo sério para o ensino da Língua Inglesa, porque permite o aluno vivenciar por meio do contexto do jogo uma narrativa instigante, que busca envolver o aluno por meio das interações virtuais simuladas para praticar a língua em estudo. Temos a intenção de usar o GA 3D como material complementar ao curso de extensão, English Online (e-3D), oferecido pelo Laboratório de Ensino e Aprendizagem de Línguas Online (LabEOn) ${ }^{4}$, na Universidade Federal de Santa Maria, portanto, exploramos no jogo funções de linguagens relacionadas também às temáticas propostas no curso, a fim de complementar o uso da língua alvo em estudo, por meio do ato de jogar.

O GA diferencia-se dos demais jogos educacionais para o ensino de línguas, porque busca por meio do ato de jogar permitir que o aluno-jogador construa o texto da narrativa pelas suas escolhas. Ao recorrer a mecânicas e elementos de jogos, comumente encontrados em jogos comerciais, planejamos por meio das missões e desafios favorecer a interação, propondo um jogo educacional que não tenha foco apenas em aspectos linguísticos, mas que favoreça a aprendizagem da língua de modo significativo, por meio de atividades que envolvem a leitura verbal e não verbal, a resolução de puzzles, pela agência e imersão no contexto do jogo.

Por isso, tomamos como referência também o livro de Sykes e Reinhard (2013) que discute os benefícios do uso didático de jogos no ensino de linguagens, salientando a importância de criar um jogo com a orientação voltada para a tomada de atitude do jogador na resolução de problemas. Desse modo, o jogador pode fazer uso do seu senso de agência e de sua liberdade de decisões influenciarem no contexto com o objetivo de afastar o jogo da lógica de expor o aluno/jogador à constante aplicação de exercícios estruturalista de forma compulsiva e descontextualizada (SYKES; REINHARDT, 2013).

${ }^{4}$ http://www.ufsm.br/labeon 
Somam-se às obras citadas, algumas contribuições de experiências prévias com o desenvolvimento e/ou análise de jogos (sérios ou comerciais) em 3D, tais como os estudos de Reis et al. (2012), Dickey (2011), Amaro (2016) e Coelho (2013), que nos auxiliaram a planejar os passos necessários para as etapas de produção do GA 3D, bem como nos advertiram a respeito de práticas de pouco sucesso já implementadas.

Ademais, com a preocupação em criar um design gráfico engajante para o $G A$, iniciamos estudos sobre os pressupostos basilares da gramática visual (NASCIMENTO; BEZERRA; HERBELE, 2011; UNSWORTH, 2006; KRESS, 2010), com a intenção de identificar padrões que possam contribuir para a construção de um design gráfico mais efetivo para comunicar os desafios do game ao jogador, por meio de considerações teóricas quanto aos sentidos contidos nos mais comuns tipos de imagens, servindo de orientação para a criação de estímulos visuais que agreguem coerência e atratividade ao contexto interno do jogo e assim complementar a narrativa visual do jogo. Como salienta Peréz-Latorre et al. (2017),

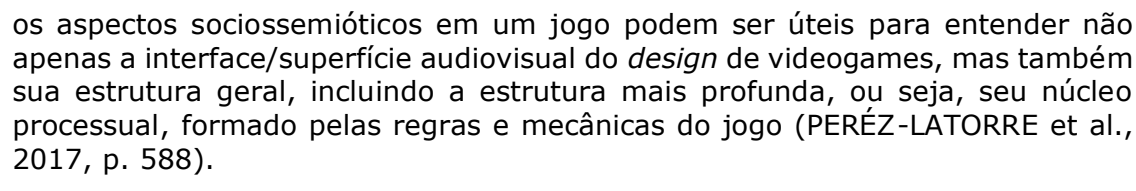

Como temos a intenção de propor o GA 3D para acesso via Android, fez-se necessário também estudar pressupostos que discutem a aprendizagem ubíqua, e o texto de Rosell-Aguilar (2017) traz um olhar voltado ao estado da arte no que se refere ao uso de aplicativos móveis em geral no ensino de línguas. As classificações propostas para avaliar aplicativos trazem características que devem ser fazer presentes naqueles que são exclusivos para o ensino de línguas, e, ainda salientam a importância de avaliar entre os aspectos tecnológicos os elementos de gamificação, ou seja, buscam avaliar se o aplicativo considera os elementos encontrados em jogos, tais como missões, desafios, imersão narrativa, pontuação, avatares, badges, ranking, entres outros, para gerar o engajamento do usuário no aplicativo.

Em se tratando de uma proposta de jogo educacional para mobile, pensamos que o GA pela sua natureza multimodal, enquanto gênero abarca diversos modos de comunicação e recursos, porém é necessário ainda buscar mais estudos que ajudem identificar critérios para avaliação de aplicativos mobile, como parâmetros para verificar se os requisitos levantados são encontrados em nosso jogo.

Além desse estudo, por meio da exposição de perguntas referentes à qualidade de um game enquanto ferramenta educacional, o artigo de Petri, Gresse von Wangenheim e Borgatto (2019) apresenta um modelo de questionário avaliativo para jogos sérios, denominado MEEGA+, como um instrumento que torna possível a inferência de alguns aspectos necessários a essas aplicações para que seu resultado seja uma experiência agregadora de conhecimentos a seus jogadores. Desse modo, compreender esse modelo nos auxiliou na seleção de aplicativos/jogos mais promissores para aplicação em contextos de ensino e, também, possibilitou a avaliação do jogo GA 3D, após a aplicação dos testes iniciais conduzidos pelos bolsistas do projeto. 


\section{Descrição do protótipo em construção: o jogo Going Abroad 3D}

Para o desenvolvimento do projeto do Jogo GA 3D, recorremos à plataforma Unity, que traz possibilidade de utilização de elementos criados por outros desenvolvedores em nosso projeto. Assim, tivemos acesso a inúmeros elementos gráficos e funcionais para o GA, pela loja oficial da Unity (UnityAsset Store), a qual possui vários componentes disponíveis para uso livre, desde simples modelos até projetos completos, que o game designer pode usar para conhecer e aprender mais sobre as possibilidades da ferramenta.

Em nossa análise prévia de jogos comerciais, evidenciamos que esses jogos em sua roteirização, de modo geral, orientam-se pelo o que é proposto por Campbell (2004), em que um problema é apresentado ao jogador, o qual ele/a busca a resolução. Por isso, baseiam-se em desafios e usam a parte gráfica para dar sustentação à narrativa. Aliando esse tipo de proposta a construção dos jogos educacionais, decidimos fazer do GA 3D um jogo em que o design e a narrativas são complementares para a busca da resolução do problema apresentado.

Nos anos de 2018 e 2019, a equipe de programação do projeto era bastante inexperiente quanto ao desenvolvimento de jogos com a ferramenta Unity (linguagem C\#), em vista disso, a maneira mais ágil e prática de realizarmos nosso projeto foi a adoção de mecanismos que atuam como partes integradas à plataforma, dando ao motor maiores e/ou melhores funcionalidades. Para encontrar tudo o que precisávamos para o desenvolvimento do jogo, realizamos uma extensa pesquisa no site da Unity, com o propósito de localizar recursos gratuitos para usufruirmos no GA, já que o projeto ainda não tem financiamento e apenas conta com duas bolsas de Iniciação científica e, do trabalho voluntário de alunos de graduação, para o desenvolvimento.

Ao elaborarmos o projeto do GA 3D, concebemos que ele precisa ser um recurso compatível com o maior número possível de computadores, ou seja, com baixos requerimentos de hardware (sem deixar de proporcionar interação e diversão ao usuário), a fim de favorecer a implementação da comunicação multimodal que sustenta o enredo, haja vista que temos a intenção de disponibilizar tal produto para uso em escolas públicas. Por isso, escolhemos uma estética cartunesca (Low Poly), com gráficos simplificados, que proporciona um acesso facilitado ao jogo e, também, tal estilo hoje possui um bom nível de adesão por parte dos jogadores.

Depois de uma vasta pesquisa na loja da Unity, constatamos que o jogo seria esteticamente mais atraente se obtivéssemos um pacote coeso de objetos para compor a cena. Então, adquirimos dois pacotes: o Polygon - City Pack ${ }^{5}$, para o cenário urbano da universidade, e o Polygon - Adventure Pack ${ }^{6}$, para complementar a flora e as paisagens naturais do cenário. Essas coleções vêm diretamente ao encontro da proposta gráfica do GA 3D.

Embora os pacotes escolhidos para orientar o design tenham nos auxiliado, o design gráfico do jogo precisa ajustes e elaboração de novos itens e avatares que são essenciais para constituir

\footnotetext{
$5_{\text {https://assetstore.unity.com/packages/3d/environments/urban/polygon-city-pack-95214 }}$

$6_{\text {https://assetstore.unity.com/packages/3d/environments/fantasy/polygon-adventure-pack-80585 }}$
} 
os cenários do jogo. Para entender melhor sobre a proposta, bem como sua narrativa, descrevemos algumas implementações já realizadas, tais como o menu inicial, a cena introdutória e alguns sistemas elaborados até o presente momento no GA 3D.

\subsection{Menu inicial e Cena introdutória}

Ao analisarmos os jogos em estudo na etapa diagnóstico, notamos que, em sua grande maioria, são apresentados o menu e a cutscene. Para criarmos o menu com logo que identifica o jogo, utilizamos o próprio software da Unity que permite usar a plataforma para elaborar um menu de inicialização(Figura 1). Porém, a plataforma não remove a logo da engine (Unity), fazendo com que a marca apareça ao final do desenvolvimento.

Para elaborar o menu foi feito um Script para auxílio da cena, introduzido diretamente no canvas do jogo. Primeiramente, foi feito a capa do jogo, para isso editamos as imagens no photoshop. Em segundo lugar, elaboramos um script para executar as funções dos botões inseridos no canvas do jogo. No menu principal optamos por apresentar os seguintes itens: New game, Continue Game, Opções, Créditos e Sair.

Figura 1 -Tela de abertura (menu-título)
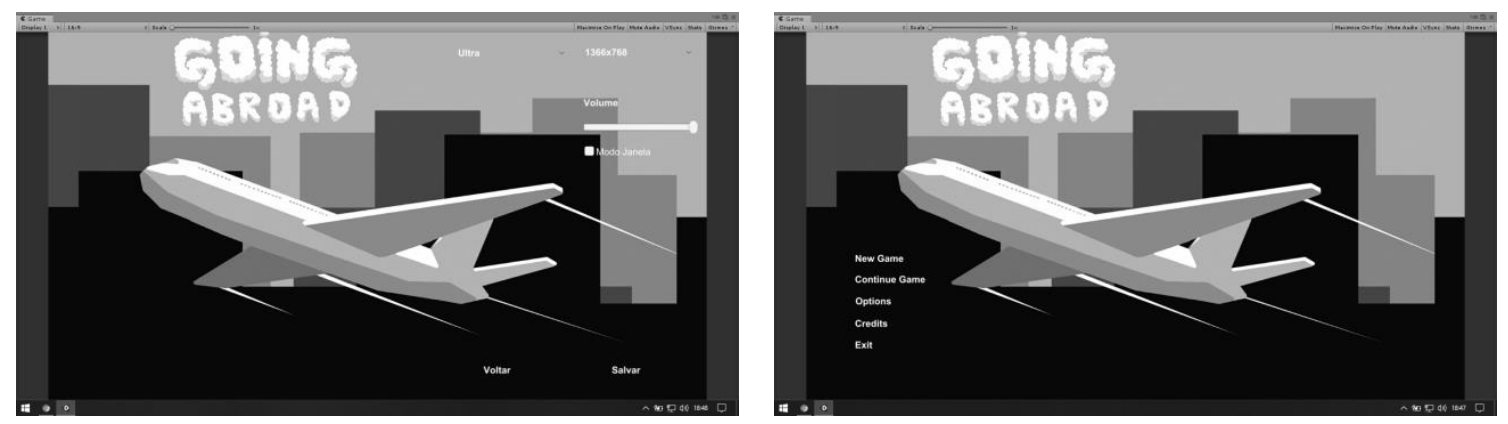

Fonte: Banco de dados dos autores.

O botão New Game é o de inicialização de um novo jogo, o Continue Game é responsável por dar continuidade a um jogo que foi iniciado anteriormente. Já o Opções traz no script uma segunda função para o menu, que permitirão a personalização do Jogo, por exemplo, o ícone Tela (define a resolução da tela), Qualidade (a qualidade das texturas), volume (aumenta/diminui sons/músicas) e o tela cheia (amplia a tela, caso o usuário esteja jogando com a tela minimizada). Ainda, no menu, temos os Créditos que irão informar a equipe de desenvolvedores e/ou pessoas que participaram do projeto do jogo e, por último, temos a opção de sair, para o jogador finalizar/desconectar do jogo.

As cenas introdutórias (cutscenes) tem a intenção de provocar o jogador ao engajamento. Ao iniciar o jogo, a cena inicial geralmente expõe o game ao aluno, contextualizando o problema que norteará sua inserção na narrativa. No GA 3D, o jogador assume o papel de um pesquisador que irá participar de um intercâmbio acadêmico em um país estrangeiro e, nesse contexto foi chamado para fazer parte de uma equipe que tem a missão de tornar possível a comunicação 
com seres interdimensionais recém-chegados à Terra, mais especificamente, no campus de uma universidade.

Ao contextualizar o problema da história, procuramos instigar o jogador na investigação e na resolução dos desafios propostos no jogo por meio de uma cena introdutória. Essa cena tem papel importante para contextualizar a narrativa e foi produzida com o objetivo de chamar a atenção do aluno/jogador ao engajamento. Para isso, tivemos a colaboração do Núcleo de Tecnologia Educacional (NTE) da UFSM para desenvolvê-la. A Figura 2 ilustra partes da cena.

Figura 2 - Cenas do jogo
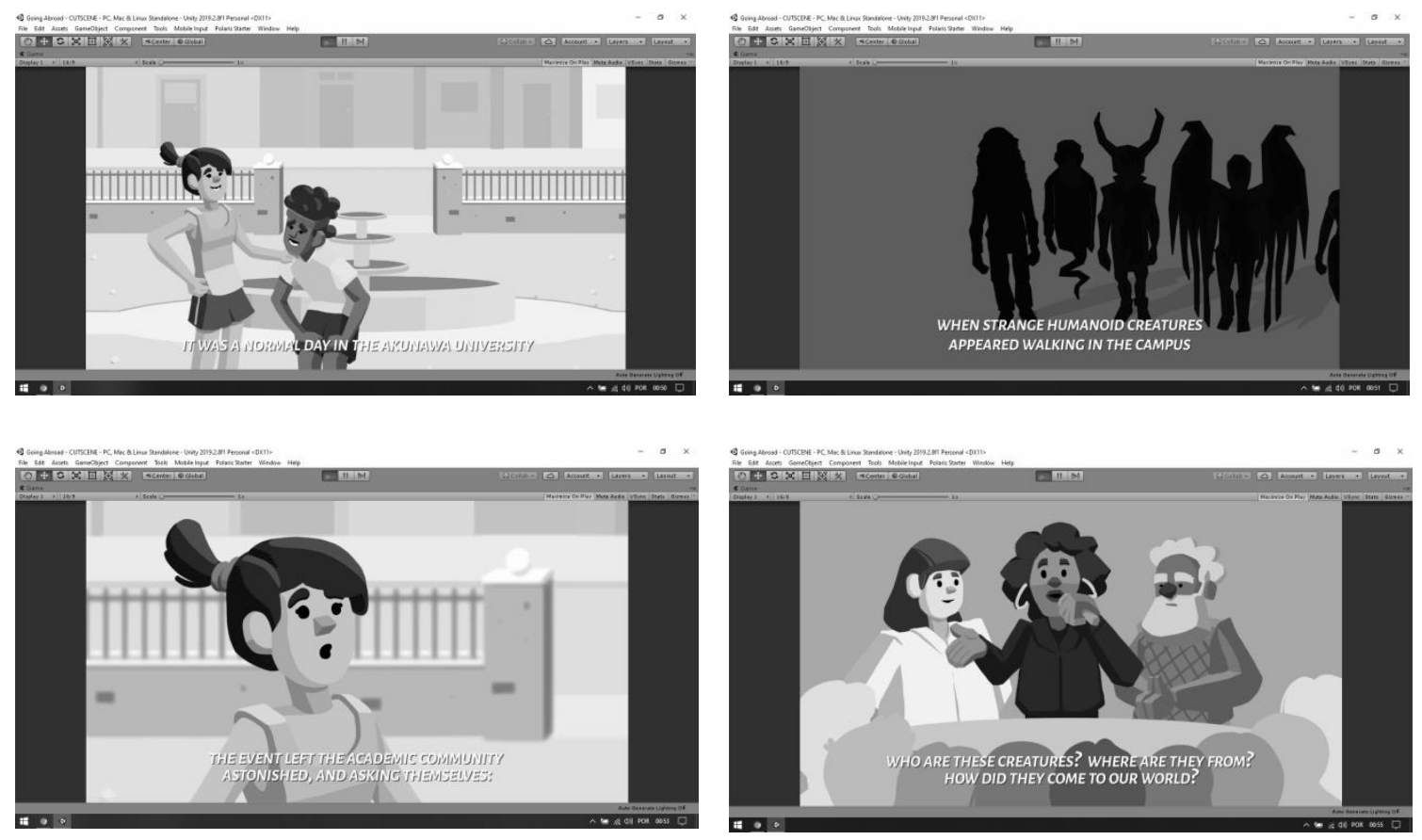

Fonte: Banco de dados dos autores.

O processo de desenvolvimento da cutscene começou com a criação de um documento compartilhado no formato de tabela, contendo a narrativa, com exemplos de imagens que poderiam montar a cena e a descrição do que elas deveriam representar. A versão inicial foi criada em forma de storyboard e, por fim, foram produzidos os quadros, que compõem a animação final. O cenário planejado para o GA 3D é de uma universidade fictícia do Canadá, por isso optamos por projetá-la de maneira minimalista e funcional, tentando manter no mapa apenas espaços úteis para o desenvolvimento da narrativa e dos desafios. A Figura 3 representa uma parte da universidade do jogo. 
Figura 3 - Cenários da entrada da Universidade em construção.
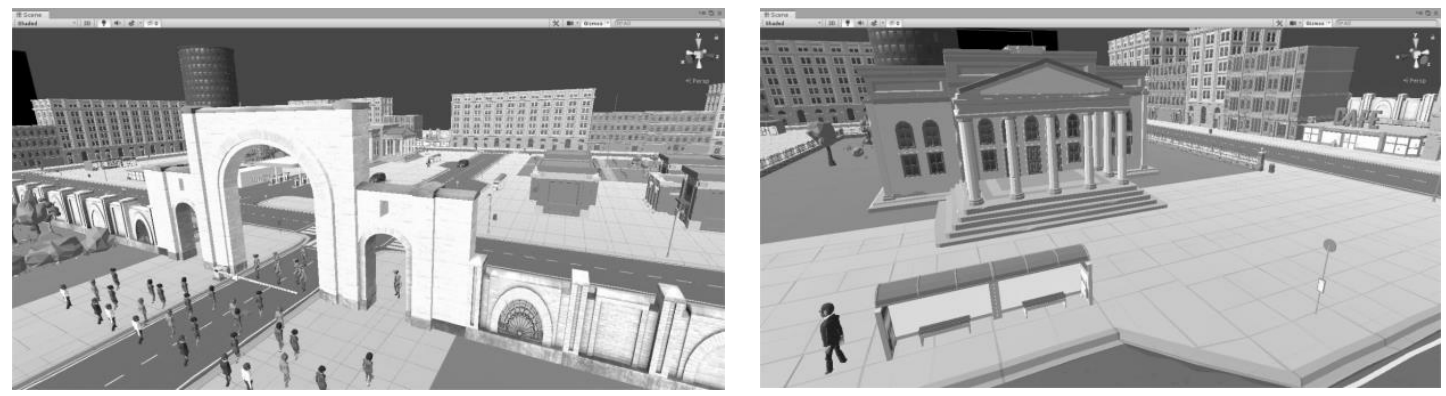

Fonte: Banco de dados dos autores.

O GA 3D trata-se de um jogo em que a interação dialógica entre personagens é a principal mecânica de sua jogabilidade. Desse modo, a narrativa adaptada conta com algumas adições oportunas ao novo estilo gráfico do jogo, que levam em conta os desafios a serem resolvidos no cenário do game. Por exemplo, na versão 3D é viável criar puzzles mais elaborados e mecânicas que consideram as dimensões extras do cenário. Além disso, os objetos têm formas mais bem definidas, o que induz o jogador a compreender melhor seus possíveis usos, as quais se somam às pistas provenientes da linguagem verbal.

Figura 4 - Interações no cenário inicial do jogo.
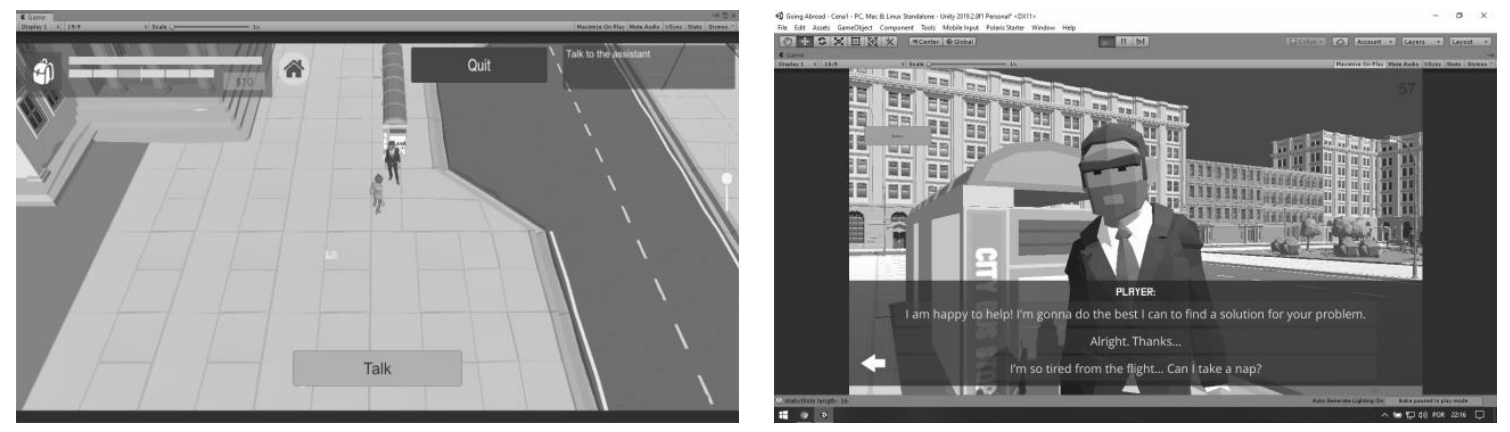

Fonte: Banco de dados dos autores

Outros recursos utilizados no projeto, até o presente momento, são os sistemas de diálogo, de câmera, de movimentação do jogador, o de ajuda linguística e o de inventário. O sistema de diálogo, por exemplo, permite que o jogador altere a narrativa enquanto suas ações e escolhas modificam a continuidade dos diálogos. Com isso, temos liberdade para adaptar o jogo conforme o jogador for progredindo na trama, e permitindo que ele explore os diferentes modos de linguagem e/ou semioses, encontradas no jogo.

O sistema de diálogo é feito a partir dos mecanismos certo, indiferente e errado para indicar as escolhas que o jogador fez, afetando diretamente o sistema de espírito, o qual se trata de um 
medidor capaz de reagir e armazenar dados sobre diversos eventos no mapa que envolvem as escolhas do jogador e o auxiliam a sentir-se incluso na história.

Figura 5 - Interface de diálogos e sistema de ajuda linguística, com algumas interações implementadas.

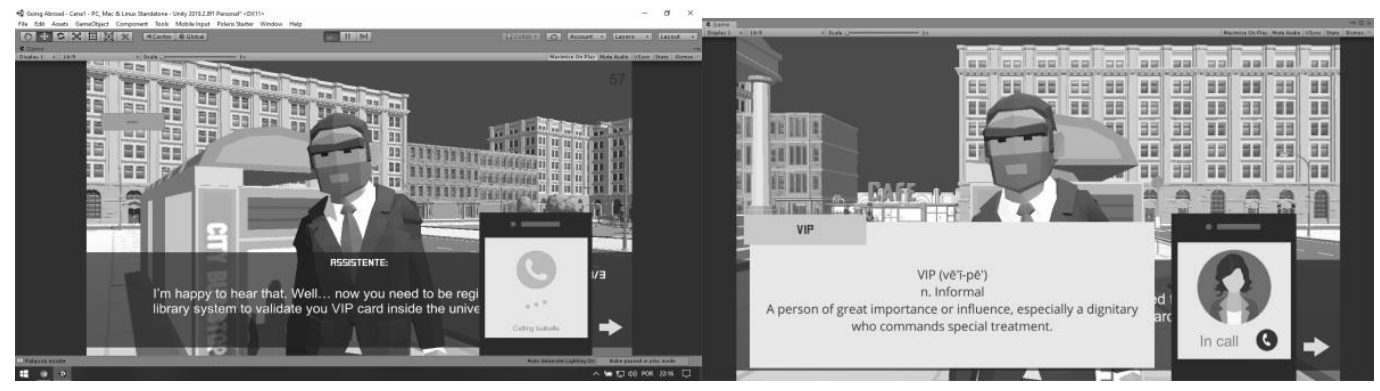

Fonte: Bancos de dados dos autores

Com relação ao sistema de ajuda linguística, buscamos dar destaque colorido a algumas palavras/expressões encontradas nos diálogos que, ao serem clicadas, trarão mais informações sobre elas. Além disso, no menu de diálogo existe ainda a opção do jogador fazer uma ligação para uma especialista virtual para perguntar o significado de uma expressão/vocabulário que não a compreendeu. Isso é feito por meio do clique na palavra, que aparece durante o diálogo com destaque em letras coloridas, como mostrado na Figura 6.

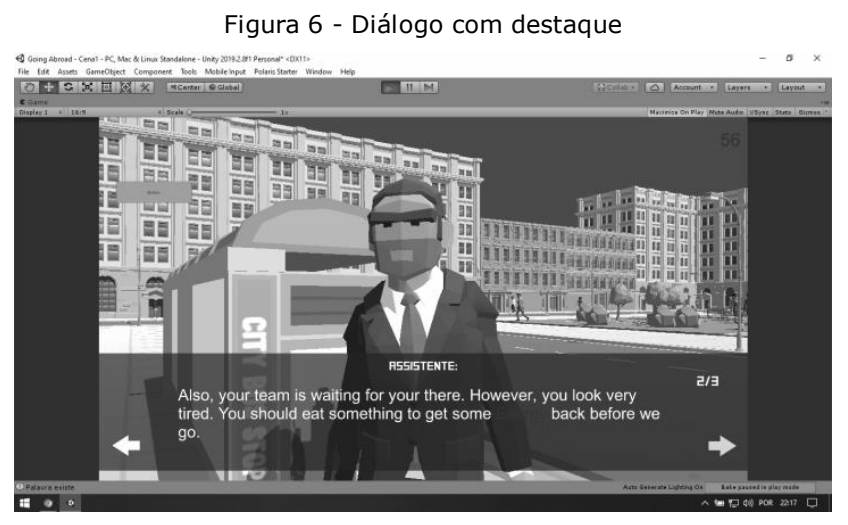

Fonte: Bancos de dados dos autores

Para garantir a agência do aluno em alguns momentos do jogo, além do sistema de escolhas de diálogo, ele ainda tem a possibilidade de editar algumas informações, sejam essas seu nome ou sua área de atuação, ao personalizar seu avatar. Também, alguns personagens (NPCs ${ }^{7}$ ) podem pedir para que o jogador execute algumas tarefas, das quais a realização interfere diretamente na barra de espírito. Exemplos de tarefas consistem na busca/coleta de itens e retorno para um NPC para efetivar a troca por uma recompensa. Na cena inicial, o desafio é comprar um café e levá-lo ao NPC que o solicitou. Para completá-lo, o jogador precisa ir até o posto, adquirir o produto (que após aquisição fica em seu inventário) e retornar ao avatar para entregar o item solicitado.

\footnotetext{
${ }^{7}$ Non-Playable Character
} 
Figura 7 - Jogador comprando o café no posto de conveniência e interação com os itens de compra.
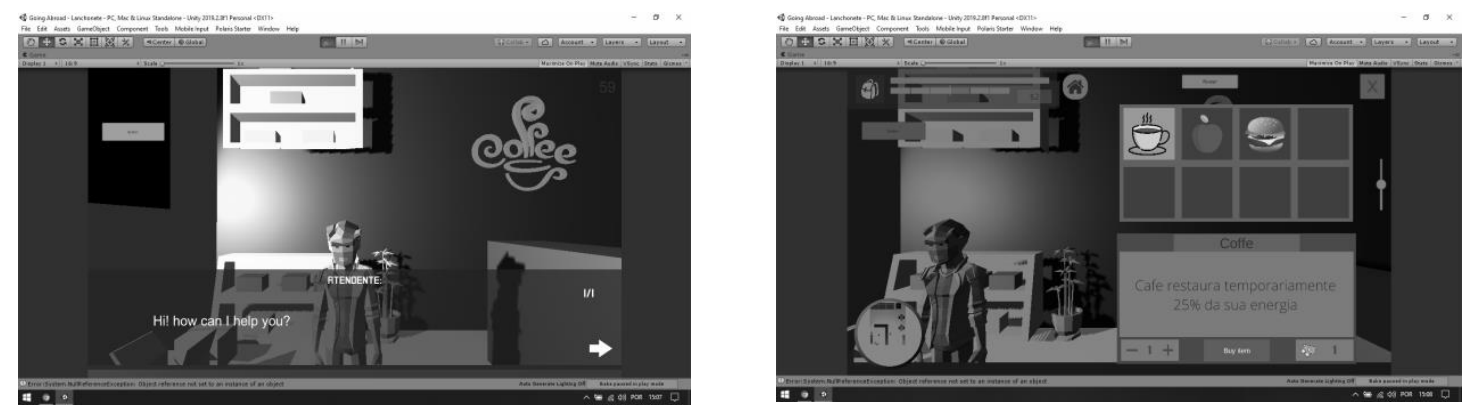

Fonte: Bancos de dados dos autores

Ao explorar o jogo, o aluno poderá coletar itens colecionáveis que serão todos incluídos no inventário. Esses itens poderão ser solicitados em missões diferentes, e, ainda, utilizados para resolver alguns mistérios que surgirão durante a narrativa, com a intenção de tornar o jogo mais imersivo e fascinante durante $o$ ato de jogar. A Figura 8 ilustra alguns itens inseridos no inventário.

Figura 8 - Inventário

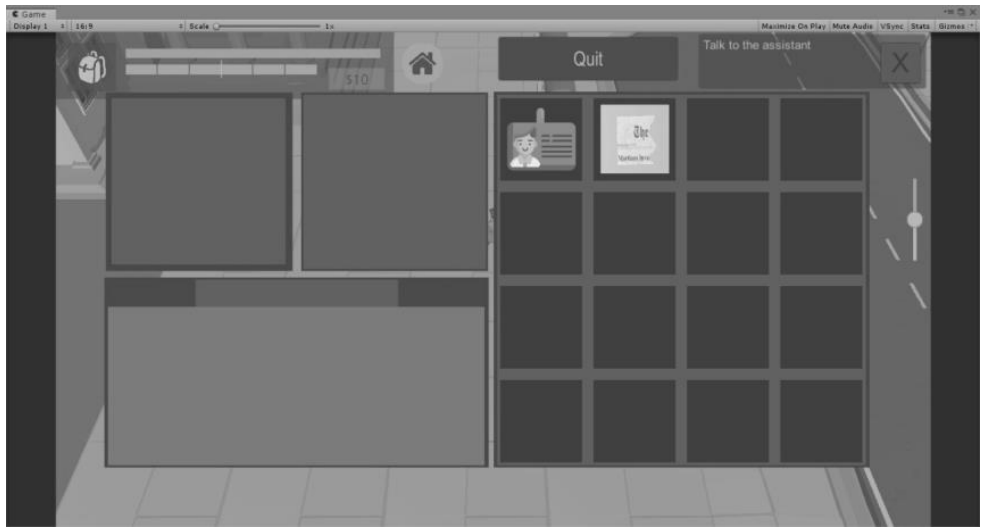

Fonte: Bancos de dados dos autores

Nossa intenção neste artigo foi apresentar a versão protótipo do GA 3D, bem como descrever alguns dos sistemas planejados, tendo em vista mostrar um trabalho colaborativo desenvolvido entre uma equipe interdisciplinar formada basicamente por uma professora orientadora e alunos(as) de graduação ${ }^{8}$ que participam do projeto de pesquisa na universidade. As atividades de pesquisa, realizadas pelos participantes, envolvem desde aprender a pesquisar pressupostos teóricos, bem como discuti-los e avaliá-los, e, ainda, aprender a manusear as ferramentas

\footnotetext{
${ }^{8}$ Neste momento fazem parte da equipe quatro alunos de graduação, os quais são de diferentes cursos de graduação e um aluno voluntário do ensino médio. Os cursos envolvidos nesse momento na equipe são da área de Letras e da Ciência da Computação.
} 
necessárias para o desenvolvimento de jogos digitais, já que tanto no curso de graduação em Letras, quanto no curso de Ciência da Computação, não há disciplinas obrigatórias curriculares em que os alunos possam cursar para aprender a desenvolver jogos, especialmente utilizando a engine Unity.

\section{Considerações Finais}

Nossa pesquisa constatou que propostas narrativas em jogos comerciais são pensadas para captar a atenção do jogador ainda que em jogos relativamente simples. Por outro lado, o game design se beneficia ao ter suas mecânicas bem integradas à narrativa do jogo. Portanto, propomos o GA 3D como um jogo que se baseia em diálogos e ações que exploram os diferentes aspectos linguísticos para construir a experiência do jogador.

Nesta fase do projeto, o protótipo do jogo conta com a cutscene introdutória e dois cenários iniciais concluídos em que o aluno é convidado a resolver os desafios ao compreender as opções linguísticas apresentadas, bem como ao resolver puzzles que o desafiem a coletar itens dentro do jogo que trarão pistas para serem utilizadas em futuras cenas do jogo.

A narrativa já tem mais fases planejadas, com desafios definidos, que ainda necessitam ser implementadas na programação do jogo. A ideia de trabalhar cooperação e colaboração no jogo é um desafio que exige dos programadores entender melhor sobre como estruturar um sistema multijogador, o que é desejável já que temos intenção de usar esse jogo em situações de ensino, em que dentro da sala de aula, o aluno colabora um com outro na construção do seus conhecimento linguístico, motivando assim a aprendizagem significativa, a interação, o suporte de andaimes durante o ato de jogar e de aprender.

Nossos próximos passos incluem dar continuidade à pesquisa por funcionalidades que tornem nosso trabalho mais ágil e tragam novas oportunidades de experimentação ao processo de desenvolvimento, tais como as possibilidades de produção em paralelo de uma versão do GA 3D para dispositivos mobile e o suporte ao sistema de multijogador. Devemos salientar que a equipe de design conta com pessoal reduzido e, por isso, a experiência de desenvolvimento traz desafios imprevistos. Dessa forma, a principal limitação do projeto é conseguirmos colaboradores fixos e com o conhecimento necessário para colaborar no design do jogo digital. No entanto, o objetivo de criar um jogo educacional digital engajante para o contexto brasileiro, que se afaste da fama de games chatos no ensino, nos motiva a implementar uma narrativa que proporcione a imersão, a interação, a construção do conhecimento de modo compartilhado e colaborativo, bem como busquem fomentar princípios de aprendizagem de bons jogos como os identificados por Gee (2005), e possibilite o aluno usar e aprender a língua inglesa, de modo lúdico e por meio da interação com as diversas linguagens em foco no jogo.

Testes pilotos já foram realizados e contemplaram a aplicação do jogo com indivíduos do público-alvo (alunos do Ensino Médio e universitários). No entanto, necessitamos coletar mais dados com alunos provenientes para uma avaliação conclusiva do jogo GA 3D, incluindo a sua inserção em contextos formais de ensino. 
A versão protótipo do jogo para PC está disponível para download no site do projeto, (http://coral.ufsm.br/labeon/index.php/seriousgames/). Como estamos em fase de testagem do jogo, adicionamos também um questionário para que os jogadores possam avaliar e nos dar retorno sobre tal produto. Esperamos que o protótipo possa ser jogado em diferentes contextos de ensino e que as colaborações advindas dessa testagem possam gerar novas reflexões sobre o processo de design de jogos educacionais digitais.

\section{Referências}

AMARO, M. O Gameplay como Processo Narrativo: uma análise de experimentos com Brothers - A Tale of Two Sons". In Congresso Brasileiro de Ciências da Comunicação, 39. Anais... São Paulo, Intercom. 2016.

CAMPBELL, J. The hero with a thousand faces: Commemorative Edition. Princeton: Princeton University Press. 2004.

COELHO, P.M.F. Uma nova forma de narrativa interativa nos games educativos: Personatges en Joc. In Hipertexto, Rio de Janeiro, v.3, n.1. 2013.

DICKEY, M.D. Murder on Grimm Isle: The impact of game narrative design in an educational game-based learning environment. In: British Journal of Educational Technology, v. 42, n. 3, p. 456-469. 2011.

FIELD, S. Manual do Roteiro. Rio de Janeiro: Objetiva. 2001.

GAZEN, Q. S.; REIS, S. C.; GOMES, A. F. Going Abroad 2D: o desenvolvimento da narrativa de um jogo sério para o ensino de língua inglesa. In: Revista Tecnologias na Educação. Ano 11, vol. 32. 2019.

GEE, J. P. Good video games and good learning. In Phi Kappa Phi Forum, v. 85, n. 2, p. 33-37. 2005.

GOMES A. F.; REIS, S. C. Descrição do Modelo Sistêmico Design com gamification para cursos online de línguas. Letras em Revista, v. 9, p. 246-264, 2018.

KRESS, G. Multimodality: A social semiotic approach to contemporary communication. New York: Routledge. 2010.

LINCK, A. J. M. Proposta de diretrizes sobre o uso e o desenvolvimento de jogos digitais para professores em formação inicial de lingua inglesa. 2018. Dissertação (Mestrado em Letras) - Universidade Federal de Santa Maria, Santa Maria, 2018. Santa Maria. p. 170. 2018.

LINCK, A. J. M.; REIS, S. C. Proposta de Diretrizes para orientar o Design de Jogos no contexto de sala de aula de Língua Inglesa. Revista Tecnologias na Educação, v. 32, p. 1-11. 2019.

NASCIMENTO, R.; BEZERRA, F.; HERBELE, V. Multiletramentos: iniciação à análise de imagens. In:Linguagem \& Ensino, Pelotas, v.14, n.2, p. 529-552, jul./dez. 2011. 
PÉREZ-LATORRE, O.; OLIVA, M.; BESALÚ, R. Videogame analysis: a social-semiotic approach, Social Semiotics, 27:5, 586-603, 2017.

PETRI, G.; GRESSE VON WANGENHEIM, C.; BORGATTO, A. F. . MEEGA+: Um Modelo para a Avaliação de Jogos Educacionais para o ensino de Computação. Revista Brasileira de Informática na Educação (RBIE) , v. 27 , p. 52, 2019.

REIS, S. C. Pesquisa e Ensino sobre Jogos Digitais na Universidade: em busca de diretrizes para o design e uso de jogos em aulas de língua inglesa. In: TOMITCH, Lêda M.B.; HEBERLE, Viviane M. (Org.). Perspectivas atuais de aprendizagem e ensino de línguas. 1 ed. Florianópolis: PPGI/UFSC, v. 1, p. 15-77. 2017.

REIS, S. C.; GAZEN, Q. S. Going Abroad 3D: Going Abroad 3D: um jogo educacional em elaboração para o ensino de língua inglesa. In: Ciclo de Palestras sobre Novas Tecnologias na Educação, 27., 2019, Porto Alegre. Anais. Porto Alegre: Centro Interdisciplinar Novas Tecnologias na Educação/ Universidade Federal do Rio Grande do Sul, p. 28-35. 2019.

REIS, S. C.; GOMES, A. F. A produção de jogos sérios interdisciplinares na universidade: novos desafios e possibilidades para o ensino da linguagem. Revista Horizontes de Linguistica Aplicada, v. 14, p. 141-166, 2016.

REIS, S. C.; SCHAF, F. M.; OLIVEIRA, A.M.; GOMES, A. F.; SOUZA, R. S.O jogo I-AI3: um protótipo em desenvolvimento. RENOTE, Revista Novas Tecnologias na Educação, v. 10, p. 1-10, 2012.

SYKES, J.M.; REINHARDT, J. Language at play: Digital games in second and foreign language teaching and learning. New Jersey: University of New Mexico; University of Arizona. 2013.

UNSWORTH, L. Image/Text Relations and Intersemiosis: Towards Multimodal Text Description For Multiliteracies Education. In 33rd International Systemic Functional Congress. University of New England, Australia. 2006.

Recebido em abril de 2020.

Aprovado para publicação em julho de 2020.

\section{Informação sobre os autores}

Susana Cristina dos Reis é professora associada, no Curso de Letras-Inglês, docente no Programa de Pós-Graduação Mestrado Profissional de Tecnologias em Rede, na UFSM. Líder do GRPesq/CNPq NUPEAD (Núcleo de Pesquisa, Ensino e Aprendizagem de Línguas a distância) e coordenadora do Laboratório de Ensino e Aprendizagem de Línguas Online (LabEon). Desenvolve pesquisas sobre ensino de línguas e tecnologias, tanto para ensino presencial quanto para a distância, focalizando o desenvolvimento de cursos online, games educativos, produção de material didático digital e formação inicial e continuada de professores para ead. País: Brasil. Email: susana.reis@ufsm.br

Quélvin Siqueira Gazen é graduando do $5^{\circ}$ semestre do Curso de Letras-Inglês, bolsista PIBIC/CNPq, participante do GRPesq/CNPq NUPEAD (Núcleo de Pesquisa, Ensino e Aprendizagem de Línguas a distância). País: Brasil. E-mail:quelvinsgazen@gmail.com 